\title{
Case Report: A case of encephalopathy presenting the lentiform fork sign on MRI in a diabetic dialysis patient -
}

\section{diabetic uremic syndrome or metformin-related}

\section{encephalopathy? [version 1; peer review: 1 approved]}

\author{
Yuri Ishizaki (1) Ryuzoh Nishizono Đ1, Masao Kikuchi', Hiroko Inagaki2, \\ Yuji Sato (iD) 1,2, Shouichi Fujimoto (D1) 1-3

\footnotetext{
${ }^{1}$ Department of Nephrology, University of Miyazaki Hospital, Faculty of Medicine, University of Miyazaki, 5200 Kihara, Kiyotake, Miyazaki, 889-1692, Japan

2Dialysis Division, University of Miyazaki Hospital, Faculty of Medicine, University of Miyazaki, Miyazaki, Japan

${ }^{3}$ Department of Hemovascular Medicine and Artificial Organs, Faculty of Medicine, University of Miyazaki, Miyazaki, Japan
}

\begin{tabular}{l}
\hline F1 First published: 11 Aug 2020, 9:969 \\
https://doi.org/10.12688/f1000research.25597.1 \\
Second version: 20 Oct 2021, 9:969 \\
https://doi.org/10.12688/f1000research.25597.2 \\
Latest published: 02 Dec 2021, 9:969 \\
https://doi.org/10.12688/f1000research.25597.3 \\
\hline
\end{tabular}

\section{Abstract}

Basal ganglia lesions showing an expansile high signal intensity on T2weighted MRI are termed the lentiform fork sign. This specific finding is mainly observed in diabetic patients with uremic encephalopathy with metabolic acidosis, although there are also reports in patients with ketoacidosis, dialysis disequilibrium syndrome, intoxication, and following drug treatment (e.g., metformin). A 57-year-old Japanese man on chronic hemodialysis for four years because of diabetic nephropathy was admitted to our hospital for relatively rapid-onset gait disturbance, severe dysarthria, and consciousness disturbance. Brain T2-weighted MRI showed the lentiform fork sign. Hemodialysis was performed the day before admission, and laboratory tests showed mild metabolic (lactic) acidosis, but no uremia. Surprisingly, metformin, which is contraindicated for patients with end-stage kidney disease, had been prescribed for six months in his medication record, and his sluggish speaking and dysarthria appeared gradually after metformin treatment was started. Thus, the encephalopathy was considered to be related to metformin treatment. He received hemodialysis treatment for six consecutive days, and his consciousness disturbance and dysarthria improved in one week. At the eight-month follow-up, the size of the hyperintensity area on MRI had decreased, while the mild gait disturbance remained. Considering the rapid onset of gait and consciousness disturbance immediately before admission, diabetic uremic syndrome may also have occurred

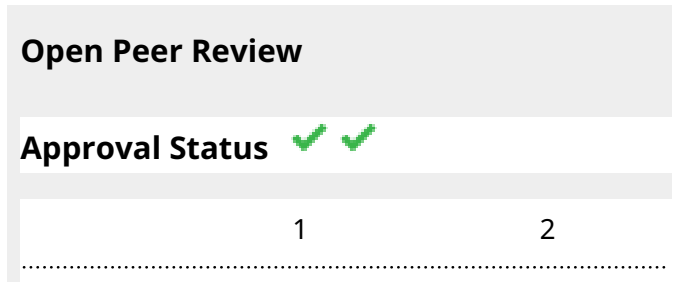

version 3

(revision)

02 Dec 2021

version 2

(revision)

20 Oct 2021

version 1

11 Aug 2020

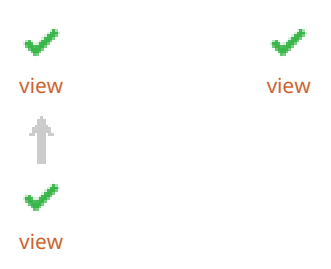

1. Shashwati Sarkar Sen ID, Mohak

Superspeciality Hospital, Prayagraj, India

2. Ping-Hsun Wu, Kaohsiung Medical University Hospital, Kaohsiung Medical University,

Kaohsiung, Taiwan

Any reports and responses or comments on the article can be found at the end of the article. 
with metformin-related encephalopathy, and resulted in the lentiform fork sign, despite the patient showing no evidence of severe uremia on laboratory data.

\section{Keywords}

lentiform fork sign, basal ganglia lesion, diabetic uremic syndrome, metformin, consciousness disturbance

\section{Corresponding author: Yuri Ishizaki (yuri_ishizaki@med.miyazaki-u.ac.jp)}

Author roles: Ishizaki Y: Writing - Original Draft Preparation; Nishizono R: Writing - Review \& Editing; Kikuchi M: Writing - Review \& Editing; Inagaki H: Writing - Review \& Editing; Sato Y: Writing - Review \& Editing; Fujimoto S: Supervision

Competing interests: No competing interests were disclosed.

Grant information: The author(s) declared that no grants were involved in supporting this work.

Copyright: @ 2020 Ishizaki Y et al. This is an open access article distributed under the terms of the Creative Commons Attribution License, which permits unrestricted use, distribution, and reproduction in any medium, provided the original work is properly cited.

How to cite this article: Ishizaki Y, Nishizono R, Kikuchi M et al. Case Report: A case of encephalopathy presenting the lentiform fork sign on MRI in a diabetic dialysis patient - diabetic uremic syndrome or metformin-related encephalopathy? [version 1; peer review: 1 approved] F1000Research 2020, 9:969 https://doi.org/10.12688/f1000research.25597.1

First published: 11 Aug 2020, 9:969 https://doi.org/10.12688/f1000research.25597.1 


\section{Introduction}

Metabolic encephalopathy with abnormal basal ganglia lesions has been reported in hemodialysis patients. Ingestion of some types of mushroom, star fruit, and drugs (e.g., anti-herpes virus drugs) can cause encephalopathy in these patients ${ }^{1-3}$. In particular, diabetic dialyzed patients can present with bilateral symmetrical low densities in the basal ganglia on brain computed tomography (CT), with a bilateral symmetrical hyperintensity in the same area and a lentiform fork sign on T2-weighted $\mathrm{MRI}^{4-10}$. In addition to diabetic uremic syndrome (DUS) ${ }^{4,5}$, the lentiform fork sign can be observed in severe metabolic acidosis $^{11-13}$, dialysis disequilibrium syndrome ${ }^{14}$, and metforminassociated encephalopathy $(\mathrm{ME})^{6,7}$. The pathogenic basis of this sign is considered to relate to cytotoxic edema based on the severity of metabolic acidosis ${ }^{8,11}$. Intensive dialysis is a therapeutic option for removing the uremic toxins, to correct metabolic acidosis and remove medications. Herein, we present a case of a 57-year-old Japanese man in whom the lentiform fork sign was a clue for the differential diagnosis of ME or DUS. Metformin tends to increase lactate production and result in metabolic acidosis in $\mathrm{ME}^{6,7,9,10}$, while chronic hyperglycemia with coexistence of uremic toxins and metabolic acidosis is the main mechanism in DUS ${ }^{4,5}$. Which of these is the main cause in our case presenting with the lentiform fork sign is discussed below.

\section{Case report}

A 57-year-old Japanese man who had been on maintenance hemodialysis three-times weekly for four years because of diabetic nephropathy developed gait and consciousness disturbance, fatigue, numbness in his left upper limb, and a slow response during conversation approximately 10 days before admission. His wife denied him taking mushrooms or star fruit, which can cause consciousness disturbance in hemodialysis patients. There were no abnormal neurologic findings on physical examination. However, bilateral symmetrical basal ganglia lesions were noted on brain CT (Figure 1a).

On admission to our hospital, his consciousness was disturbed, such as he only could open his eyes following calling, and he had difficulty sitting alone. He showed a tonic planter reflex on physical examination. His blood pressure was 190/91 $\mathrm{mmHg}$, and his heart rate was 104 beats per min. Atrial blood gas showed a $\mathrm{pH}$ of 7.37 , bicarbonate ion of $18.1 \mathrm{mEq} / \mathrm{L}$, and lactic acid of $6.2 \mathrm{mmol} / \mathrm{L}$. Serum calcium, vitamin B1, and blood aluminum levels were all within the acceptable range. Kidney function data sampled the day after dialysis, blood urea nitrogen, and serum creatinine were consistent with dialysis. His $\mathrm{HbA} 1 \mathrm{c}$ was $5.8 \%$ on admission.

Brain MRI showed bilateral symmetrical basal ganglia lesions with an expansile high signal intensity (lentiform fork sign) on T2-weighted sequences (Figure 1b), which was not seen on MRI taken one-year prior when he developed a right thalamic lacunar infarction.

In his medication history, he had taken metformin for six months. His wife said that his sluggish speaking and dysarthria appeared gradually after starting metformin treatment (Figure 2). His plasma metformin concentration was extremely high $(25,700 \mathrm{ng} / \mathrm{mL})$. Thus, we considered that metformin may have initially caused the encephalopathy. However, we
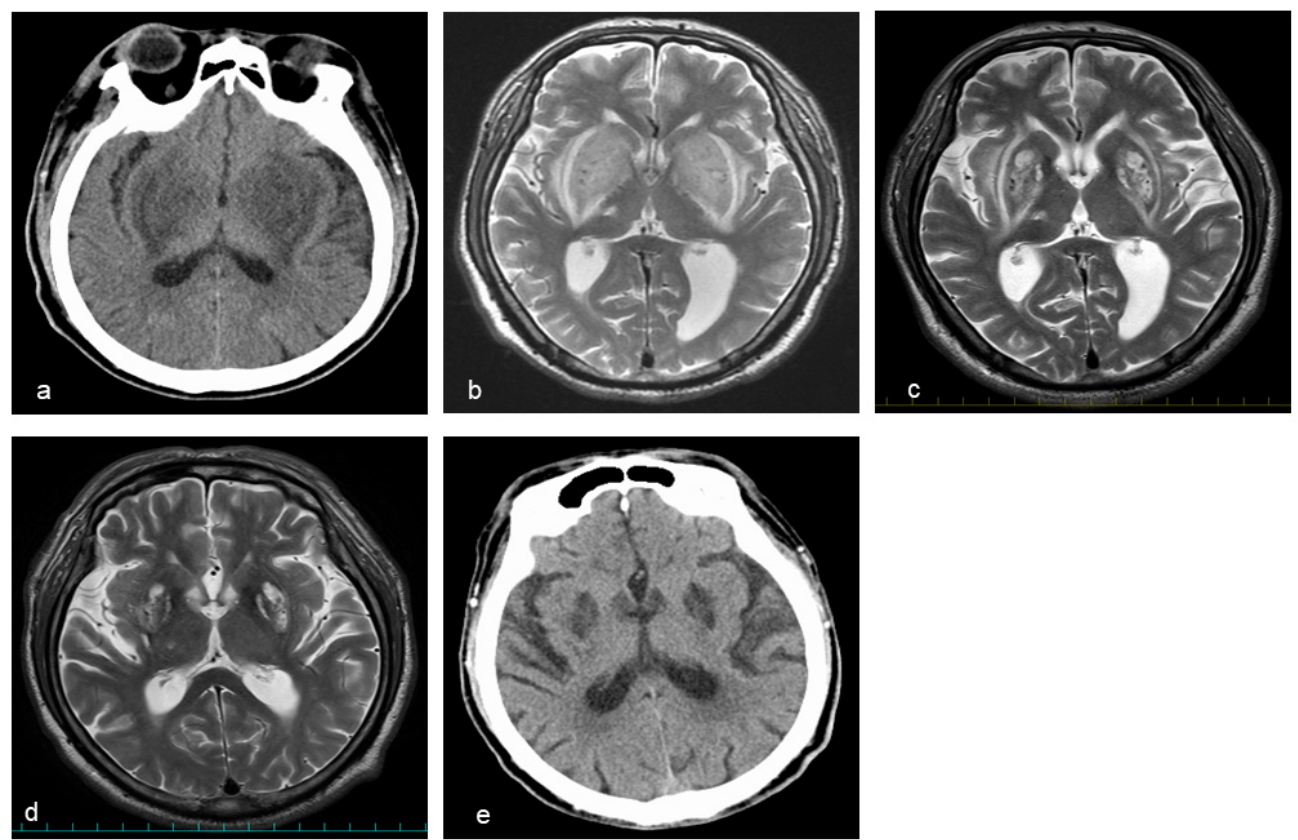

Figure 1. a, e Head computed tomography (CT) and b-d head MRI (T2-weighted image). a, b High-resolution lesions in the bilateral symmetrical basal ganglia were evident at admission. $\mathbf{c}$, $\mathbf{d}$ The bilateral symmetrical basal ganglia lesions gradually improved on the $18^{\text {th }}$ hospital day and at three-month follow-up. e However, the basal ganglia lesions remained at eight-month follow-up. 


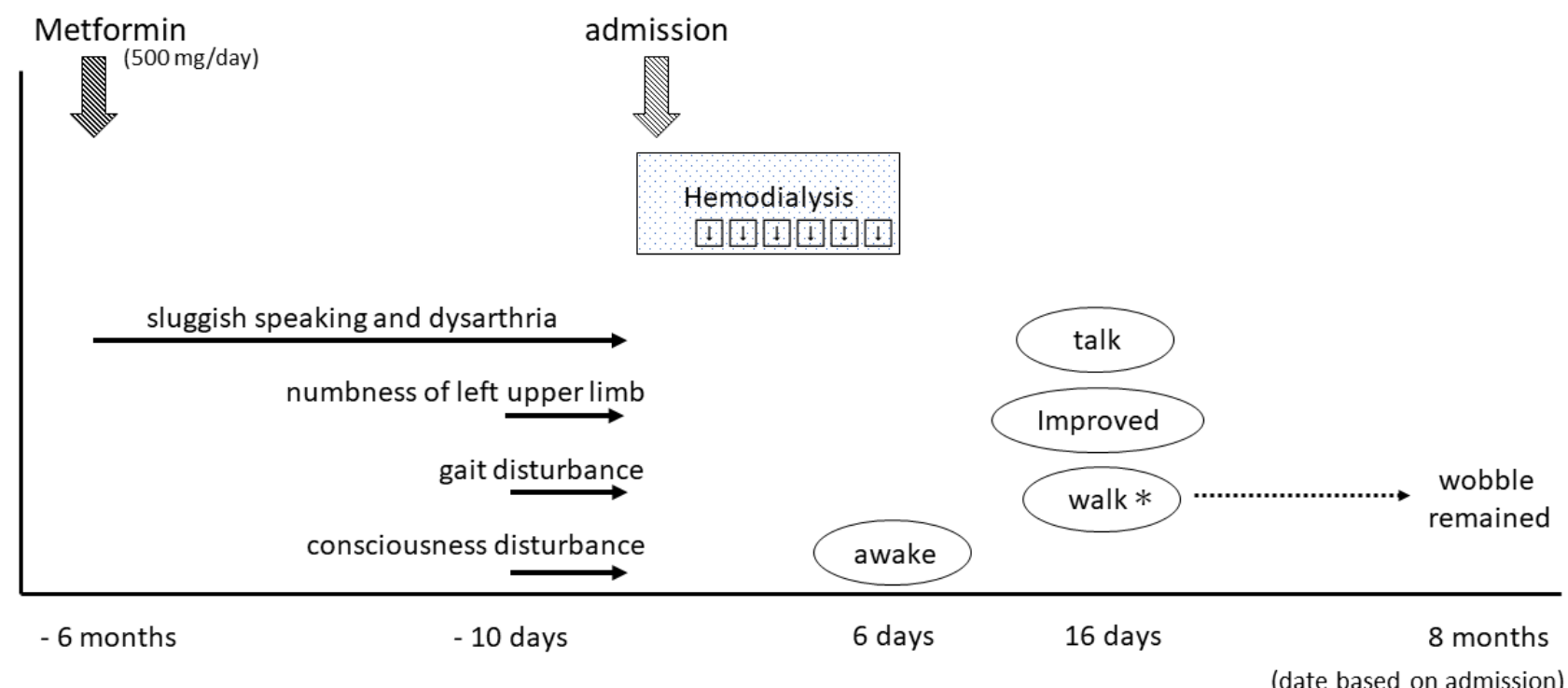

Figure 2. The patient started metformin treatment at six months prior to admission. Since that time, he developed gradual symptoms of sluggish speaking and dysarthria, while numbness of his left upper limb, gait disturbance, and consciousness disturbance appeared 10 days before admission. He received emergency consecutive hemodialysis for six days, after which he awoke, and was gradually able to walk and talk. *Walking was possible, but wobbling during walking remained at eight-month follow-up.

also considered the possibility of DUS, because his gait and consciousness disturbance appeared relatively rapidly approximately 10 days before hospitalization. DUS typically occurs in uncontrolled uremic patients with diabetic mellitus.

In either case, we stopped metformin treatment, and immediately performed intensive hemodialysis (four hours per day) for six days after hospitalization to remove metformin and uremic toxin, and to correct metabolic acidosis. The first dialysis session reduced his lactic acid levels from 6.0 to $1.3 \mathrm{mmol} / \mathrm{L}$. After six consecutive sessions of hemodialysis, his consciousness was restored, and his tonic planter reflex disappeared. After starting meals, linagliptin was chosen as an anti-diabetic drug to replace metformin.

On the $18^{\text {th }}$ hospital day, T2-weighted brain MRI revealed a modest improvement in the lentiform fork sign (Figure 1c). The patient was gradually able to sitting alone, walk, and talk with staff and his wife. He was discharged from our hospital within one month.

At three-month follow-up, the lentiform fork sign was further improved on brain MRI (Figure 1d). However, at eight months after the onset, he still complained movement disorders, such as a wobble when walking and body tilting when resting. Brain lesions were still evident on CT scan (Figure 1e).

\section{Discussion}

Herein, we report a diabetic hemodialysis patient with consciousness disturbance who presented with the lentiform fork sign on T2-weighted brain MRI. This finding appears in the basal ganglia, which is vulnerable to addictive toxins and metabolic products ${ }^{8,12}$. The lentiform fork sign is comprised of the following elements: 1) the lateral arm, formed by the edematous external capsule and extending from the anterior end of the putamen to the stem; 2) the stem, created by merging of the edematous external and internal capsules at the inferoposterior end of the putamen; and 3) the medial arm, which extends from the stem anteriorly up to one third of the medial edge, where it splits into two slightly less T2/FLAIR-hyperintense branches engulfing the globus pallidus ${ }^{11,12,15}$. In the present case, brain MRI showed the same expansile high signal intensity (Figure 1b). The lentiform fork sign is rare but non-specific. Thus, a differential diagnosis should be considered (Table 1$)^{8,11-15}$, of which ME or DUS may be the cause in the present case.

The use of metformin in dialyzed patients can cause drug accumulation in the brain, leading to neurological abnormalities, difficulties of speech and walking, with worsening of sensory disturbance, tiredness, drowsiness, and weakness (i.e., ME) $)^{6,7,10}$. Metformin is first-line drug used in type 2 diabetes mellitus. However, it is contraindicated in patients with an estimated glomerular filtration rate $<30 \mathrm{~mL} / \mathrm{min} / 1.73 \mathrm{~m}^{2}$, because of an increased risk of lactic acidosis. Acidosis can damage the basal ganglia, resulting in cytotoxic edema ${ }^{7}$, which is sometimes irreversible despite intensive hemodialysis to remove metformin and lactic acid, and to correct acidosis.

Alternatively, DUS is characterized by acute or subacute progression with a variety of movement disorders such as gait disorders, dysarthria, parkinsonism, and consciousness disturbance. 
DUS can cause bilateral symmetrical basal ganglia lesions on brain CT and T2-weighted $\mathrm{MRI}^{4,5}$ in patients with diabetic nephropathy, even if they are not on hemodialysis. To date, approximately 30 cases of DUS have been reported, many of which are Asian. The reported risk factors of DUS include a high level of HbA1c before and at hemodialysis, and increasing

\section{Table 1. Differential diagnosis of pathological conditions presenting with the lentiform fork sign ${ }^{8,11-15}$.}
a) Uremic encephalopathy *
b) Severe metabolic acidosis
c) Ketoacidosis
d) Dialysis disequilibrium syndrome
e) Intoxication (methanol, ethylene glycol, etc)
f) Drug-induced (metformin)

*The lentiform fork sign mainly occurs in patients with diabetic kidney disease. metabolic acidosis. Hyperglycemia damages the microvasculature, resulting in a fragile vascular smooth muscle, and the accumulation of uremic toxins and/or metabolic acidosis can damage the blood-brain-barrier, leading to altered metabolism and homeostasis in the brain. This can result in basal ganglia injury, including angiogenic edema, which is reversible and shows favorable prognosis.

The clinical presentation in our case was not helpful for differentiating $\mathrm{ME}$ and DUS, because these symptoms were indistinguishable (Table 2). Initial hemodialysis improved lactic acidosis, although intensive hemodialysis for six consecutive days was required to improve his consciousness. The lentiform fork sign on MRI improved at first, although brain CT findings at eight-month follow-up showed low density signals in those regions, and his neurological sequelae remained, suggestive of continued cytotoxic edema. ME was likely the main cause of injury in our case. Nevertheless, the patient's condition worsened relatively rapidly before admission, similar to that seen in DUS. DUS can also contribute to cytotoxic edema in the basal ganglia, and has a variable progression. Thus, DUS may have also contributed to the encephalopathy in our case.

\begin{tabular}{|c|c|c|c|}
\hline & ME & DUS & Present case \\
\hline Clinical findings & $\begin{array}{c}\text { sensorium, tiredness, } \\
\text { dysarthria, gait } \\
\text { disorder, } \\
\text { consciousness } \\
\text { disturbance }\end{array}$ & $\begin{array}{l}\text { dysarthria, gait } \\
\text { disorder, } \\
\text { parkinsonism, } \\
\text { consciousness } \\
\text { disturbance }\end{array}$ & $\begin{array}{c}\text { tiredness, dysarthria, } \\
\text { gait disorder, } \\
\text { consciousness disturbance }\end{array}$ \\
\hline Onset & $\begin{array}{l}\text { gradually and } \\
\text { subacute }\end{array}$ & acute and subacute & $\begin{array}{l}\text { gradually (dysarthria) and subacute } \\
\text { (gait and consciousness disturbance) }\end{array}$ \\
\hline Acidosis & Lactic acidosis & Metabolic acidosis & Lactic \& metabolic acidosis \\
\hline Uremia & - & + & - \\
\hline Hyperglycemia & - & + & - \\
\hline CT & low density area & low density area & low density area \\
\hline MRI (T2-weighted) & high intense lesion & high intense lesion & high intense lesion \\
\hline $\begin{array}{l}\text { Characteristic of } \\
\text { edema }\end{array}$ & cytotoxic & vasogenic & cytotoxic \\
\hline Therapy & $\begin{array}{l}\text { stop metformin } \\
\text { intensive hemdialysis }\end{array}$ & intensive hemdialysis & intensive hemdialysis \\
\hline Prognosis & remained & good & remained \\
\hline
\end{tabular}

ME, metformin-associated encephalopathy; DUS, diabetic uremic syndrome. 
In summary, we report a diabetic hemodialysis patient with encephalopathy presenting as the lentiform fork sign derived from ME and/or DUS. In dialysis patients showing gait and consciousness disturbance, the lentiform fork sign on brain CT and T2-weighted MRI may be useful for differential diagnosis.

\section{Data availability}

All data underlying the results are available as part of the article and no additional source data are required.

\section{Consent}

Written informed consent for publication of their clinical details and clinical images was obtained from the patient.

\section{Acknowledgements}

We thank Edanz Group (https://en-author-services.edanzgroup. $\mathrm{com} /$ ) for editing a draft of this manuscript.

\section{References}

1. Akiyama $\mathrm{H}$, Matsuoka $\mathrm{H}$, Okuyama T, et al: The acute encephalopathy induced by intake of sugihiratake mushroom in the patients with renal damage might be associated with the intoxication of cyanide and thiocyanate. Food Safety. 2015; 3(1): 16-29. Publisher Full Text

2. Auxiliadora-Martins M, Alkmin Teixeira GC, da Silva GS, et al: Severe encephalopathy after ingestion of star fruit juice in a patient with chronic renal failure admitted to the intensive care unit. Heart Lung. 2010; 39(5): 448-452.

PubMed Abstract | Publisher Full Text

3. Delluc $A$, Mocquard $Y$, Latour $P$, et al.: Encephalopathy and acute renal failure during acyclovir treatment. Rev Neurol (Paris). 2004; 160(6-7): 704-706. PubMed Abstract | Publisher Full Text

4. Wang $\mathrm{HC}$, Cheng SJ: The syndrome of acute bilateral basal ganglia lesions in diabetic uremic patients. J Neurol. 2003; 250(8): 948-955.

PubMed Abstract | Publisher Full Text

5. Finelli PF, Singh JU: A syndrome of bilateral symmetrical basal ganglia lesions in diabetic dialysis patients. Am J Kidney Dis. 2014; 63(2): 286-288. PubMed Abstract | Publisher Full Text

6. Kang YJ, Bae EJ, Seo JW, et al.: Two additional cases of metformin-associated encephalopathy in patients with end-stage renal disease undergoing hemodialysis. Hemodial Int. 2013; 17(1): 111-115.

PubMed Abstract | Publisher Full Text

7. Simon SP, Thomas J: Metformin-associated encephalopathy in hemodialysis. Indian J Nephrol. 2019; 29(3): 194-196.

PubMed Abstract | Publisher Full Text | Free Full Text

8. Kim DM, Lee $\mathrm{IH}$, Song $\mathrm{CJ}$ : Uremic encephalopathy: MR imaging findings and clinical correlation. ANJR Am J Neuroradiol. 2016; 37(9): 1604-1609. PubMed Abstract | Publisher Full Text
9. Abdel SC, Carland JE, Graham GG, et al:: Is the use of metformin in patients undergoing dialysis hazardous for life? A systematic review of the safety of metformin in patients undergoing dialysis. Br J Clin Pharmacol. 2019; 85(12): 2772-2783.

PubMed Abstract | Publisher Full Text | Free Full Text

10. Vecchio S, Giampreti A, Petrolini VM, et al.: Metformin accumulation: lactic acidosis and high plasmatic metformin levels in a retrospective case series of 66 patients on chronic therapy. Clin Toxicol (Phila). 2014; 52(2): 129-35.

PubMed Abstract | Publisher Full Text

11. Kumar G, Goyal MK: Lentiform Fork sign: a unique MRI picture. Is metabolic acidosis responsible? Clin Neurol Neurosurg. 2010; 112(9): 805-812. PubMed Abstract | Publisher Full Text

12. Grasso D, Borreggine $C$, Perfetto $F$, et al.: Lentiform fork sign: a magnetic resonance finding in a case of acute metabolic acidosis. Neuroradiol J. 2014; 27(3): 288-292. PubMed Abstract | Publisher Full Text | Free Full Text

13. Saini AG, Sreevilasan $S K$, Singh $P$, et al.: Lentiform fork sign due to severe metabolic acidosis. BMJ Case Rep. 2017; 2017: bcr2017222871.

PubMed Abstract | Publisher Full Text | Free Full Text

14. da Rocha AJ, Maia AC Jr, da Silva CJ, et al.: Lentiform fork sign in a child with dialysis disequilibrium syndrome: a transient MRI pattern which emphasizes neurologic consequence of metabolic acidosis. Clin Neurol emphasizes neurologic consequen
Neurosurg. 2013; 115(6): 790-792. Neurosurg. 2013; 115(6): 790-792.
PubMed Abstract | Publisher Full Text

15. Beltz EE, Mullins ME: Radiological reasoning: hyperintensity of the basal ganglia and cortex on FLAIR and diffusion-weighted imaging. AJR Am J Roentgenol. 2010; 195(3 Suppl): S1-8. PubMed Abstract | Publisher Full Text 


\section{Open Peer Review}

\section{Current Peer Review Status:}

\section{Version 1}

Reviewer Report 27 September 2021

https://doi.org/10.5256/f1000research.28250.r95340

(C) 2021 Sen S. This is an open access peer review report distributed under the terms of the Creative Commons Attribution License, which permits unrestricted use, distribution, and reproduction in any medium, provided the original work is properly cited.

\section{Shashwati Sarkar Sen}

Department of Reproductive Medicine and Surgery, Mohak Superspeciality Hospital, Prayagraj, Uttar Pradesh, India

Summary: It is prudent to avoid Metformin in Diabetic patients with chronic renal insufficiency. Metformin toxicity can cause lactic acidosis induced encephalopathy eventually leading to multiorgan failure and death. Lentiform fork sign is a specific MRI finding in basal ganglia of these patients probably due to vasogenic edema induced by metabolic acidosis. Suspicion about Metformin intake will help in an early diagnosis and treatment.

A few suggestions to the authors:

1. Restrict the number of words in the title. Too many medical terms are used.

2. Case Report: Correction - Arterial Blood Gas analysis.

3. Mention the Glasgow Coma Score.

4. DUS may have a subacute presentation. Yoshiko Nishimura et $a .^{2}$ have reported a case of Diabetic Uremic Syndrome where the clinical features developed over 3 months. In your case, ME seems to be the primary diagnosis and DUS may be considered as a differential diagnosis rather than a contributory factor.

Add these References:

1. Metformin-induced encephalopathy: the role of thiamine ${ }^{1}$.McGarvey et al. (2018) suggested that Metformin may cause thiamine deficiency in patients with end-stage diabetic renal failure, resulting in a specific type of encephalopathy. A quick resolution of the signs and symptoms was observed on stopping the drug in these patients.

2. A case of subacute Parkinsonism presenting as bilateral basal ganglia lesions by MRI in Diabetic uremic Syndrome. ${ }^{2}$ 


\section{References}

1. McGarvey C, Franconi C, Prentice D, Bynevelt M: Metformin-induced encephalopathy: the role of thiamine.Intern Med J. 48 (2): 194-197 PubMed Abstract | Publisher Full Text

2. Nishimura $Y$, Shibata $K$, Funaki T, Ito $H$, et al.: [A case of subacute parkinsonism presenting as bilateral basal ganglia legions by MRI in diabetic uremic syndrome].Rinsho Shinkeigaku. 2013; 53 (3): 217-23 PubMed Abstract | Publisher Full Text

Is the background of the case's history and progression described in sufficient detail? Yes

Are enough details provided of any physical examination and diagnostic tests, treatment given and outcomes?

Yes

Is sufficient discussion included of the importance of the findings and their relevance to future understanding of disease processes, diagnosis or treatment?

Yes

Is the case presented with sufficient detail to be useful for other practitioners?

Yes

Competing Interests: No competing interests were disclosed.

Reviewer Expertise: Endocrine disorders, Assisted reproductive technology, Infertility, Gynaecology, Obstetrics

I confirm that I have read this submission and believe that I have an appropriate level of expertise to confirm that it is of an acceptable scientific standard.

Author Response 16 Oct 2021

Yuri Ishizaki, University of Miyazaki, 5200 Kihara, Kiyotake, Miyazaki, Japan

Dear Dr. Shashwati Sarkar Sen,

Thank you for your valuable comments about my case report. We respond to each suggestion as follows.

1) Restrict the number of words in the title. Too many medical terms are used. As suggested by the reviewer, we shorten the title to "A Case of Encephalopathy Presenting the Lentiform Fork Sign on MRI in a Diabetic Dialysis Patient".

2) Case Report: Correction - Arterial Blood Gas Analysis.

Thank you for pointing it out. We corrected "Atrial blood gas" to "Arterial blood gas analysis". 
3) Mention the Glasgow Coma Score.

We mentioned the Glasgow Coma Scale Score of E3V4M6 in the first line of the case report section.

\section{4) DUS may have a subacute presentation. Yoshiko Nishimura et al. have reported a case of Diabetic Uremic Syndrome where the clinical features developed over 3 months. In your case, ME seems to be the primary diagnosis and DUS may be considered as a differential diagnosis rather than a contributory factor.}

Thank you for your comment. In our case, there was not enough evidence to diagnose ME. The first reason was the thiamin level was not decreased, even though metformin may induce thiamin deficiency. (We added serum thiamin value in the part of the case presentation.) Furthermore, thiamin deficiency can be caused by malnutrition and loss of water-soluble vitamins in the hemodialysis progression, but the patient did not have the symptoms of weight loss and seemed not to be undernourished. Secondly, the level of metabolic (lactic) acidosis on admission was also much mild not so high. Thirdly, as shown in Fig. 2, although the patient had had sluggish speaking and dysarthria and these findings had been gradually worsening six months before starting taking metformin, the relatively rapid-onset gait disturbance, severe dysarthria, and consciousness disturbance had appeared ten days before admission, which was a subacute progression. We could say that it was difficult to distinguish between ME and DUS, just considering the appearance of the findings. That is why we cannot necessarily diagnose $M E$, and we listed the two differential diagnoses, ME and/or DUS.

We added the following sentences in the Discussion section:

According to the previous reports, hemodialysis patients are at risk for thiamin deficiency which is induced to encephalopathy, because they are in the condition of malnutrition and tend to lose water-soluble vitamins in the hemodialysis procedure [16, 17]. Furthermore, thiamin deficiency may be a possible mechanism in metformin-induced encephalopathy [18]. In our case, the thiamin level was not decreased and severe lactic acidosis was not observed. In addition to these, the occurrence of gait disturbance, severe dysarthria, and consciousness disturbance was subacute even though sluggish speaking and dysarthria had been gradually worsening six months before starting taking metformin as shown in Fig.2, and the patient was neither malnutrition nor weight loss. That is why it was not necessarily ME.

\section{References}

We also read the two references which you indicated. According to Reference \#1, thiamine must be a key to diagnose Metformin-induced encephalopathy. In the part of that we showed the thiamin level of our case, we quoted reference \#1. On the other hand, we did not add reference \#2 because it is written in Japanese and we thought that reader cannot understand it well.

Furthermore, we quoted two more references to mention that our case is not necessarily $\mathrm{ME}$ in the perspective of thiamin level in hemodialysis patients (Szu-Chun $\mathrm{H}$ et al, AJKD, 2001).

Sincerely yours, 
Yuri Ishizaki

Competing Interests: None

The benefits of publishing with F1000Research:

- Your article is published within days, with no editorial bias

- You can publish traditional articles, null/negative results, case reports, data notes and more

- The peer review process is transparent and collaborative

- Your article is indexed in PubMed after passing peer review

- Dedicated customer support at every stage

For pre-submission enquiries, contact research@f1000.com 